\title{
Immunohistochemical Demonstration of Blood Vessels Alpha-Actin Down-Regulation in LPS-Treated Pregnant Mice
}

\author{
B. ZAVAN ${ }^{1}$, A. GIUSTI-PAIVA ${ }^{1}$, R. SONCINI ${ }^{1}$, A. M. DO AMARANTE-PAFFARO ${ }^{1}$, \\ V. A. PAFFARO Jr${ }^{1}$ \\ ${ }^{1}$ Integrative Animal Biology Laboratory, Biomedical Science Institute, Federal University \\ of Alfenas, Alfenas, Minas Gerais, Brazil
}

Received March 20, 2012

Accepted May 22, 2012

On-line August 8, 2012

\begin{abstract}
Summary
Lipopolysaccharide (LPS), produced by gram-negative bacteria, mediates vasodilatation, changing the action of contractile smooth muscle by increasing expression of nitric oxide synthase and prostaglandin. For the first time we demonstrate, by immunohistochemical methods, that administration of LPS to pregnant mice causes a-actin-mediated down-regulation of contractile filaments in uterine blood vessels, thereby potentially increasing vessels permeability, blood supply, and immune cells homing to this environment, culminating in the reestablishment of uterine homeostasis.
\end{abstract}

\section{Key words}

Alpha-actin • Blood vessels • Uterus

\section{Corresponding author}

Paffaro Jr VA, Biomedical Science Institute, UNIFAL-MG, 700 Gabriel Monteiro da Silva Street, Alfenas, Minas Gerais, Brazil. Post Code: 37130-000. E-mail: paffaroj@gmail.com

Smooth muscle cells of blood vessels have a high amount of contractile proteins such as $\alpha$-actin, which are affected by local mediators such as endothelin- 1 and TGF$\beta 1$ (transforming growth factor $\beta 1$ ) (Fisher et al. 1997). It is known that LPS of gram-negative bacteria mediates vasodilator activation, which changes smooth muscle contraction by increasing expression of nitric oxide synthase and prostaglandin (Schildknecht et al. 2004). Furthermore, smooth muscle cells of blood vessels express TLR4 and CD14, which are capable of signaling in response to even low amounts of LPS in blood circulation, resulting in decreased expression of genes whose products are related to contraction, such as the $\alpha$-actin gene (Sandbo et al. 2007).

To evaluate the influence of administration of LPS on the organization of contractile filaments in uterine blood vessels during pregnancy, SWISS pregnant mice (gestation day 10) received LPS (100 $\mu \mathrm{g} / \mathrm{kg}$ ) by a carefully and distant from the implant intraperitoneal injection. These mice had their implantation sites collected after 30 minutes, 1 hour, 2 hours and 4 hours $(\mathrm{n}=10)$. A control group received only saline $(\mathrm{n}=10)$. After deparaffinization, the histological sections of ten implantation sites of each experimental group ware washed with $\mathrm{PBS}$ (phosphate buffer saline $0.05 \mathrm{M}$ ), incubated with $1 \% \mathrm{H}_{2} \mathrm{O}_{2}$ and $1 \%$ PBS/BSA for 30 minutes each, and overnight at $4{ }^{\circ} \mathrm{C}$ with primary antibody: anti- $\alpha$-actin 1:100 (Sigma Chemical Co. USA). After further washing with PBS the histological sections were incubated with secondary antibody: biotinylated anti-rabbit 1:500 (Sigma Chemical Co. USA) for 1 hour and Streptoavidin-peroxidase for 1 hour (Sigma Chemical Co. USA). The sections were rinsed with PBS and revealed by diaminobenzidine (Sigma Chemical Co. USA) (Figure 1). A negative control for $\alpha$-actin immunohistochemistry was performed by omitting the primary antibody.

The $\alpha$-actin antibody reacted with myometrium (Figure 1B and 1C) and with smooth muscle cells of the blood vessels from the myometrium and endometrium (Figure 1B and 1D) in normal mice, but not in $\alpha$-actinnegative control sections (Figure 1A). 


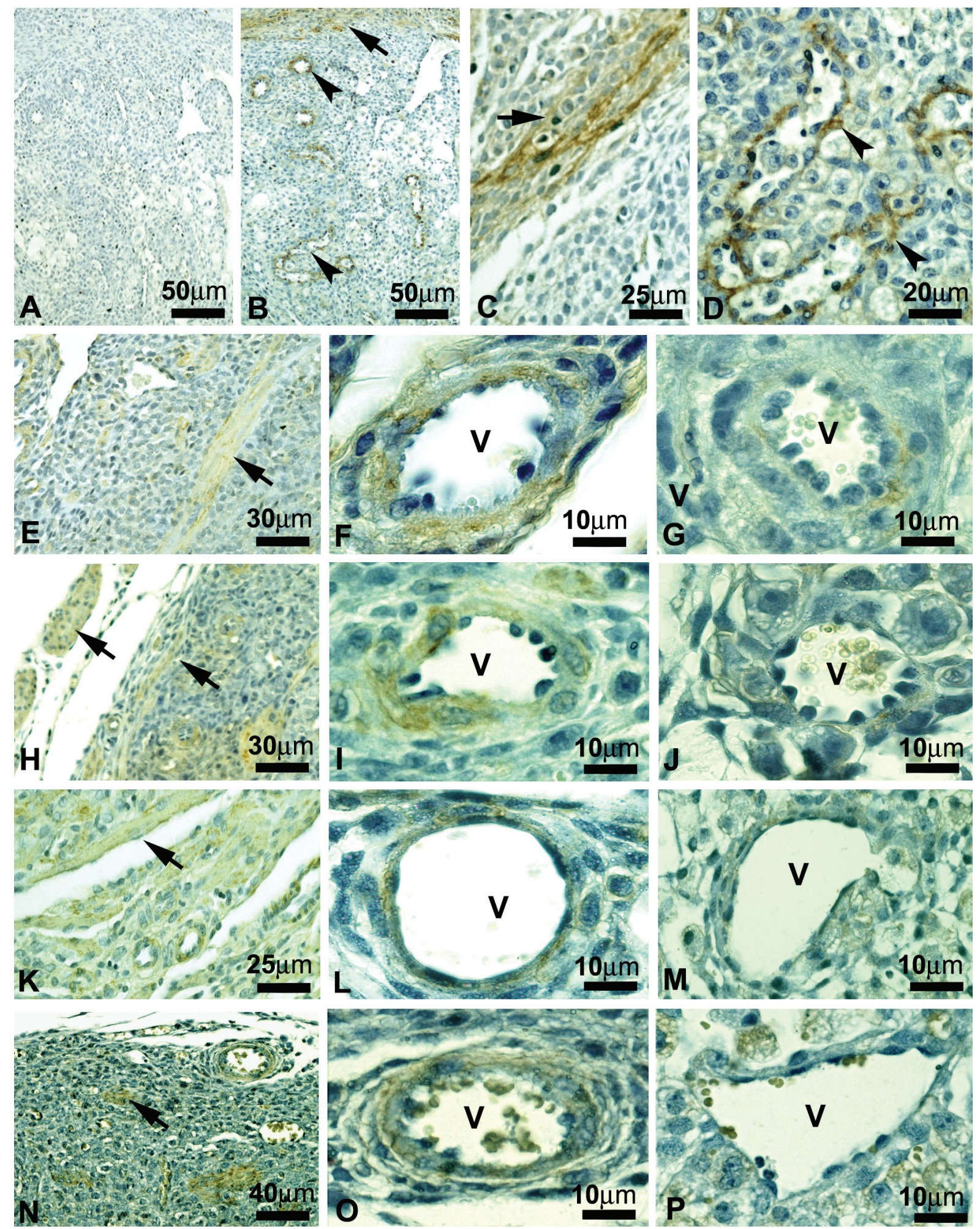

Fig. 1. Photomicrographs of mouse uterine histological sections at gd 10 after imunocytochemistry using antibody to the a-actin. Negative control developed in PBS injected mouse (i.e. control mouse) (A). Positive reaction on the myometrium (arrow) and smooth muscle cells of blood vessels (arrowhead) in the same mouse uterus showed in A (B). Large magnification of control uterus showing a positive reaction on the miometrium (arrow) and on blood vassels (arrowhead), respectively (C and $\mathbf{D}$ ). Sections from a mouse uterus after LPS injection (E-P). Thirty minutes after LPS administration, a weak reaction on the myometrium (arrow) (E), blood vessels (F) and very weak reaction in endometrial blood vessel (G) was observed. One hour after LPS exposure, a weak reaction in the myometrium (arrow) $(\mathbf{H})$, blood vessels (I) and non-reactivity of endometrial blood vessels (J) was seen. After 2 hours $(\mathbf{K}, \mathbf{L}$ and $\mathbf{M})$ and 4 hours of LPS exposure (N, O and $\mathbf{P}$ ), the myometrium (arrow) (K and N), blood vessels ( $\mathrm{L}$ and $\mathrm{O}$ ) and endometrial blood vessel ( $\mathrm{M}$ and $\mathrm{P}$ ) showed the same reaction pattern observed as seen 1 hour after LPS administration. Blood vessels (V). Peroxidase-DAB and Harris Hematoxylin. 
After LPS administration (30 minutes to 4 hours) a low expression for $\alpha$-actin in the smooth muscle cells on the myometrium (Figures $1 \mathrm{E}, 1 \mathrm{H}, 1 \mathrm{~K}$ and $1 \mathrm{~N}$ ) and also on smooth muscle cells of the blood vessels from the myometrium (Figures 1F, 1I, 1L and 1O) was observed. However, the reaction for $\alpha$-actin was markedly lower on smooth muscle cells of blood vessels from the endometrium after 30 minutes from LPS administration (Figure $1 \mathrm{G}$ ), and the $\alpha$-actin reaction was negative on smooth muscle cells of blood vessels from this region after 1 hour until 4 hours of LPS administration (Figures $1 \mathrm{~J}, 1 \mathrm{M}$ and $1 \mathrm{P}$ ).

This study demonstrates for the first time that LPS may cause disassembly of contractile filaments from uterine blood vessels of pregnant mice, especially in the mesometrial region where uNK cells are localized (Stewart and Peel 1981, Paffaro Jr et al. 2003, Bulmer and Lash 2005).

Renaud et al. (2011) have intraperitoneally injected LPS in rat during gestation day 14.5. Contradictory to our results they showed an increasing of uterine artery resistance and reduced spiral arteriole flow velocity. Therefore, it is reasonable to propose that the LPS injection in different days of pregnancy could trigger heterogeneous response by the pregnant mouse organism. Supporting our study, Hazan et al. (2010) demonstrated that the reduction process of smooth muscle cells in blood vessels is a natural phenomenon of vascular remodeling during late pregnancy. According to these authors, this remodeling is due to the activation of uterine Natural Killer cells and macrophages leading to lyses of vascular smooth muscle cells, cell death and resorption.

Therefore it seems reasonable to hypothesize that the LPS administration in the midpregnancy could cause changes to the uterus, leading to accelerated vascular remodeling, thus increasing the permeability of blood vessels, blood supply and probably leukocyte homing to the uterine environment as a mechanism to restore homeostasis after sepsis in murine pregnancy.

\section{Conflict of Interest}

There is no conflict of interest.

\section{Acknowledgements}

The authors are grateful to Fundação de Ampáro a Pesquisa do Estado de Minas Gerais (FAPEMIG) for support this work.

\section{References}

BULMER JN, LASH GE: Human uterine natural killer cells: a reappraisal. Mol Immunol 42: 511-521, 2005.

FISHER SA, IKEBE M, BROZOVICH F: Endothelin-1 alters the contractile phenotype of cultured embryonic smooth muscle cells. Circ Res 80: 885-893, 1997.

HAZAN AD, SMITH SD, JONES RL, WHITTLE W, LYE SJ, DUNK CE: Vascular-leukocyte interactions: mechanisms of human decidual spiral artery remodeling in vitro. Am J Pathol 177: 1017-1030, 2010.

PAFFARO VA Jr, BIZINOTTO MC, JOAZEIRO PP, YAMADA AT: Subset classification of mouse uterine natural killer cells by DBA lectin reactivity. Placenta 24: 479-488, 2003.

RENAUD SJ, COTECHINI T, QUIRT JS, MACDONALD-GOODFELLOW SK, OTHMAN M, GRAHAM CH: Spontaneous pregnancy loss mediated by abnormal maternal inflammation in rats is linked to deficient uteroplacental perfusion. J Immunol 186: 1799-1808, 2011.

SANDBO N, TAURIN S, YAU DM, KREGEL S, MITCHELL R, DUBLIN NO: Downregulation of smooth muscle $\alpha$-actin expression by bacterial lipopolysaccharide. Cardiovasc Res 74: 262-269, 2007.

SCHILDKNECHT S, BACHSCHMID M, BAUMANN A, ULLRICH V: COX-2 inhibitors selectively block prostacyclin synthesis in endotoxin-exposed vascular smooth muscle cells. FASEB J 18: 757-759, 2004.

STEWART I, PEEL S: Granulated metrial gland cells in the virgin and early pregnant mouse uterus. $J$ Anat 133: 535 $541,1981$. 